\title{
CONGENITAL AORTIC STENOSIS
}

\author{
BY \\ F. RONALD EDWARDS AND RICHARD S. JONES \\ From the Royal Liverpool Children's Hospital and the Departments of Surgery and Child Health, \\ Liverpool University
}

Of 3,022 patients with congenital heart disease studied in the heart clinic of the Royal Liverpool Children's Hospital during the last five years, 120 presented with signs of uncomplicated aortic stenosis giving an incidence of $4 \%$ of all cases of congenital heart disease. Swan, Wilkinson, and Blount (1958) noted an incidence of $5 \%$ of all patients in their congenital heart disease clinic. It has been reported twice as commonly in males as in females and the ratio was just $2: 1$ in our series. Most patients present with an isolated stenosis of the aortic valve or the outflow tract of the left ventricle, but in some other cardiovascular abnormalities are associated. In our experience, in addition to the 120 with uncomplicated aortic stenosis, there was an associated patent ductus arteriosus (in 9 subjects), ventricular septal defect (5), coarctation of the aorta (3), pulmonary stenosis (2), mitral stenosis (2), atrial septal defect (2), dextrocardia (2), vascular ring (1), transposition of the great vessels (1), and tricuspid atresia (1).

The cause of the development of the condition in foetal life is obscure, but a comparison can naturally be drawn with isolated congenital pulmonary stenosis. The form of cusp fusion and annular hypoplasia, where present, is similar in both conditions as also is the relative incidence of valvar to subvalvar stenosis. Combined aortic and pulmonary stenosis must be rare, and apart from the two cases not included in the series, we have only seen a single example at operation, one of our two cases with supravalvar stenosis.

Of the 120 known cases in the heart clinic, 44 have been submitted to detailed investigation. Thirty-two of these patients have been operated upon, of whom four died, and altogether 10 cases were available for post-mortem examination.

The following account of the condition and its treatment is based upon this material.

\section{Physio-pathology}

Three forms of stenosis were found: valvar, subvalvar, and supravalvar.
VALVAR STENOSIS.-Characteristically the individual valve cusps have not fully developed into the normal thin, mobile structure required for efficient function. Each is thickened and shortened from the base to the free margin. One, usually the non-coronary cusp, may be rudimentary. The cusp edges appear to have fused in part, giving a number of variations of structure (see Fig. 11), the general effect being that of a bicuspid valve. The cusp fusion has the effect of a partial diaphragm across the annulus, bracing it and limiting dilatation with systole, which may result in quite marked narrowing, suggesting a general hypoplasia. Lack of mobility is probably almost as important as reduction in the length of the free margin of the valve cusps in the production of obstruction to flow. Fibrous nodules form on the edges or the body of the cusps and seem to increase in size and number as age advances. In two infants who died of the condition at 3 weeks and 5 weeks of age, the surfaces of the cusps were fairly uniform and although they were appreciably thickened no nodules were visible or palpable. An infant who died at 6 months had thickened irregular cusps and a small ring. A 3-year-old child had thickened and slightly nodular cusps. Six children who came to necropsy between the ages of 11 and 17 years and all those observed at operation had thickened, nodular cusps. The nodules in those who died were examined histologically for calcium and this was present in one subject only, the valve of a 14-year-old girl. It was not visible on radiographic examination of the valve at necropsy. The only adult in this series, a man of 26 years, known to have had aortic stenosis for 12 years, had obvious calcium in the valve at operation. Atheroma was seen in the aorta within one centimetre of the valve and in the outflow tract of the left ventricle between the mitral and aortic rings, extending to the surfaces of the cusps in six of the seven specimens from patients between 3 and 17 years of age. The location of these atheromatous patches was constant and corresponded to the areas on the aorta, the ventricle, and the base of 
the cusps where calcification is found in cases of "calcific aortic stenosis" in middle age. It is likely, though not proven, that a proportion of the patients with " calcific aortic stenosis" recognized for the first time in adult life were originally suffering from congenital aortic stenosis of a valvar type and that subsequent cusp and mural calcification has occurred, progressively limiting the cusp movement and so increasing the functional stenosis.

The opening in the valve may be centrally situated, and results in a uniform post-stenotic dilatation of the first part of the aorta. Occasionally it is eccentrically located and this may produce a lateral aneurysmal dilatation where the jet of blood comes into contact with the aortic wall. In all patients examined at operation the dilated portion of the aorta was thinned and more friable than normal. Post-stenotic dilatation was present in 24 out of the 26 cases of valvar stenosis.

The left ventricular myocardium is markedly thickened and the lumen may be reduced to a narrow slit. Histologically the individual fibres of the myocardial syncytium are enlarged. In childhood fatty changes are not seen and fibrosis was not observed in the myocardium of the two infants. Fibrosis was observed in six of the seven necropsy specimens of subjects between 3 and 17 years. Observation during operation of these hypertrophied left ventricles showed a "musclebound " state with little visible external movement in marked contrast to the free contraction of the normal right ventricle. The left coronary vessels do not appear to be greatly enlarged, but the intramuscular vascular bed may be severely compressed by the muscle mass, producing a raised resistance. It is for this reason, in all probability, that these ventricles are so sensitive to falls in the systemic pressure and that anoxic changes, leading to arrest, rapidly follow even minor degrees of hypotension.

Subvalvar Stenosis.- Subvalvar stenosis was found in five of the 32 operated cases and one of the necropsy specimens (Fig. 1). This in four patients took the form of a thin diaphragm consisting of little more than endocardium and lying just underneath the valve or at 1 or $2 \mathrm{~cm}$. down the left ventricular outflow tract. One of these patients also had a valvar stenosis. No similar structure appears to be found under the pulmonary valve.
FIG. 1. Diagrammatic representation of the type of subvalvar stenosis found at operation. The depth of muscle tissue found between the aortic and mitral valve has only been assessed as this cannot be directly estimated at operation.
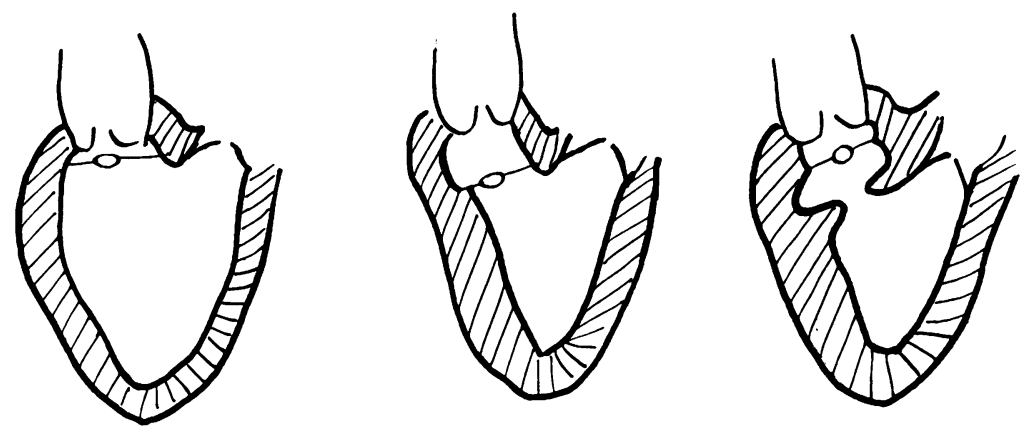

SUBVALVAR STENOSIS (DIAPHRAGMATIC)

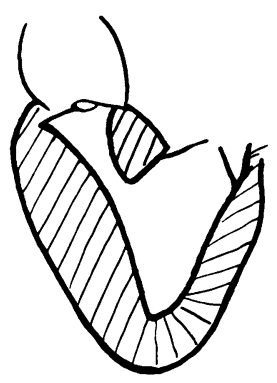

SUBVALVAR STENOSIS (INFUNDIBULAR)

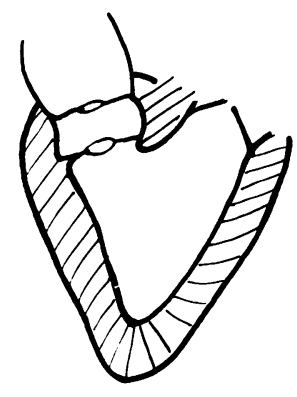

VALVAR 2 SUBVALVAR STENOSIS 
A thick fibrous diaphragm was present in one patient in the outflow tract, similar to that found in some cases in the right ventricle.

A muscular thickening of the whole outflow tract may be found and one example of this occurred in the whole series in a child who died suddenly at the age of 11 years. One in the series operated on had an infundibular muscular hypertrophy, very similar to that found below a stenotic pulmonary valve, which relaxed during ventricular diastole. Generalized stenosis of the outflow tract may be associated with familial hypertrophy of the left ventricle (Goodwin, Hollman, Cleland, and Teare, 1960 ; Hollman, Goodwin, Teare, and Renwick, 1960) and we have seen one case of this not included in this series. In subaortic stenosis there is usually little post-stenotic dilatation of the aorta, but if there is an immediate subvalvar diaphragm the jet effect may be very similar to that produced by a valvar stenosis. Post-stenotic dilatation was marked in one of our cases but very slight in the other three.

SuPRAVAlvar Stenosis.- Supravalvar stenosis was found in two cases. A concentric narrowing of the aorta for 2 to $3 \mathrm{~cm}$. just above the origin of the coronary vessels was seen. The lumen of the aorta was reduced markedly and the appearance was that of a piece of thick-walled rubber tubing, the wall in this area being much thicker than in the normal aorta. In both cases the coronary ostia were involved in the start of the narrowed area. Characteristically the coronary vessels are greatly enlarged secondary to the transmission of the raised intraventricular pressure, and in both our cases the condition was recognized on opening the pericardium (Fig. 2). The situation of the coronary ostia in relation to the stenotic area raises serious technical problems if excision is contemplated. One of these subjects had an associated pulmonary valvar stenosis.

\section{Clinical Features}

Of the 120 children with congenital aortic stenosis studied, five died during infancy and in each case death was preceded by a short period of congestive cardiac failure, usually initiated by a respiratory infection. Six died later in childhood ( $2 \frac{1}{2}$ to 17 years); in contrast to the infants, death occurred suddenly in this group. In addition two died after operation using a non-perfusion technique.

Forty were selected on clinical and cardiographic grounds as probably having a degree of stenosis that required operative relief. The left ventricular pressure was measured by percutaneous

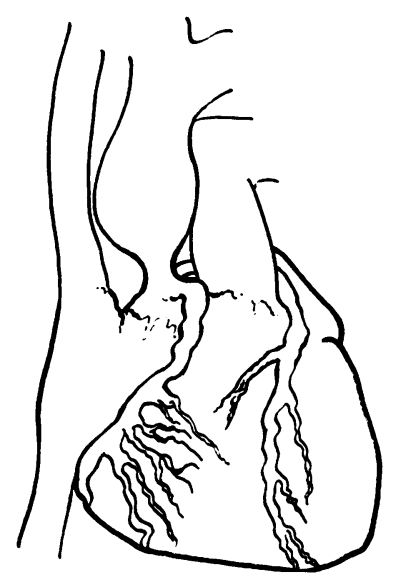

SUPRAVALVAR AORTIC STENOSIS

FIG. 2. Supravalvar aortic stenosis. The marked enlargement of the coronary vessels is immediately apparent on opening the pericardium.

puncture of the ventricle in all subjects in this group and the brachial artery pressure was measured simultaneously. In 30 the peak systolic gradient ranged from 60 to $166 \mathrm{~mm}$. $\mathrm{Hg}$ and in the remaining ten from 10 to $50 \mathrm{~mm}$. $\mathrm{Hg}$. Twenty-eight of those with gradients over $60 \mathrm{~mm}$. $\mathrm{Hg}$ were subsequently submitted to operation using a perfusion technique and the main clinical features of these are shown in Table $I$.

Excessive breathlessness on exertion was the only symptom and this was never marked except in the adult of 26 years, who had severe impairment of exercise tolerance and angina of effort. It was common in both the high (over $60 \mathrm{~mm}$. Hg) and low (under $60 \mathrm{~mm} . \mathrm{Hg}$ ) gradient groups $(65 \%$ of the former and $50 \%$ of the latter) and its character was very constant: these children could run as fast but not so far as others of the same size.

The pulse was not helpful as an indication of severity of the stenosis. It was observed to be small in $14(47 \%)$ of the high-gradient group and two $(20 \%)$ of the low-gradient group. The left ventricular impulse was more helpful; it was excessive in $18(60 \%)$ of the high-gradient group and in only one $(10 \%)$ of the low-gradient group. The blood pressure was not significantly different in the two groups.

A thrill was palpable in the aortic area, the suprasternal notch, and over the carotid arteries in all subjects, but it was less intense in a number of those in the low-gradient group. A thrill was 
TABLE I

OPERATIONS FOR CONGENITAL AORTIC STENOSIS (PERFUSION TECHNIQUE)

\begin{tabular}{|c|c|c|c|c|c|c|}
\hline \multirow[b]{2}{*}{ No. Age Sex } & \multicolumn{3}{|c|}{ Pre-operative } & \multirow{2}{*}{$\begin{array}{c}\text { Size of } \\
\text { Ori- } \\
\text { fice } \\
\text { (mm.) }\end{array}$} & \multicolumn{2}{|c|}{ Post-operative } \\
\hline & $\begin{array}{l}\text { Dias- } \\
\text { tolic } \\
\text { Bruit }\end{array}$ & B.P. & $\underset{\text { ient }}{\text { Grad- }}$ & & B.P. & $\begin{array}{l}\text { Dias- } \\
\text { tolic } \\
\text { Bruit }\end{array}$ \\
\hline
\end{tabular}

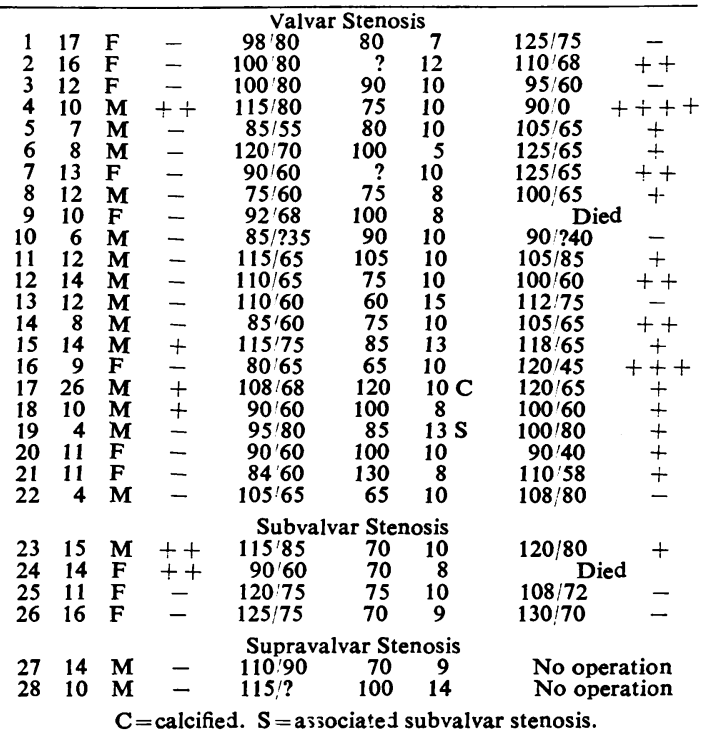

TABLE II PHONOCARDIOGRAPHIC FEATURES Peak systolic gradient $(\mathrm{mm} . \mathrm{Hg}) \quad 10-59 \quad 60-166$

Number of subjects

Number with ejection click Systolic murmur (\% cycle length) $\quad 70-85$

Second sound

$\begin{array}{cc}10 & 30 \\ 9 & 21 \\ 70-85 & 80-100 \\ 0.02-0 \cdot 04 & 0-0.03 \text { (sec.) } \\ \text { (sec.) } & \text { or paradoxical }\end{array}$

palpable at the apex in three (one subvalvar stenosis and two pure valvar stenosis). A harsh systolic murmur accompanied the thrill and was maximal in the aortic area in 25 of the 40 subjects, was equally loud in the pulmonary area in 13 and at the apex in one subject. It was maximal in the pulmonary area in one subject.

A mitral diastolic murmur was audible at the apex in four subjects. Its significance is uncertain but if it is a prominent sign, the possibility of associated congenital mitral stenosis should be considered. Aortic regurgitation considered sufficient to contraindicate operation was only encountered once in the whole series. Of the six patients submitted to operation in whom it was present to some degree, it was associated with a valvar stenosis in four and a subvalvar stenosis in two.

\section{Phonocardiographic Features}

The phonocardiographic features are shown in Table II and Fig. 3. An ejection click was common in the high- and low-gradient groups. It was absent in the four patients with subvalvar and the two with supravalvar stenosis and present in 19 of the 22 with valvar stenosis submitted to operation. It therefore has some diagnostic significance, as pointed out by Lees, Hauck, Starkey, Nadas, and Gross (1962). There was a fairly well defined relationship between the length of the systolic murmur expressed as a percentage of the cycle length and the peak systolic gradient. The interval between aortic and pulmonary closure was rather more closely related to peak

FIG. 3. Relationship of interval between aortic and pulmonary valve closure to peak systolic gradient.

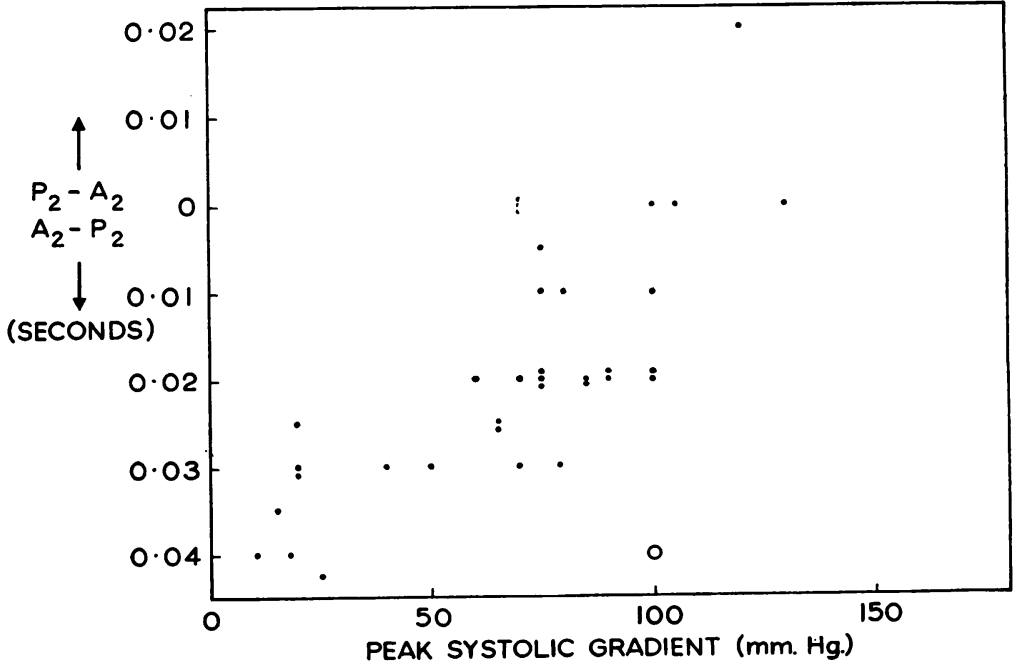


systolic gradient (Fig. 3). The majority of those with a significant gradient (over $60 \mathrm{~mm} . \mathrm{Hg}$ ) had a single second sound on auscultation or an interval which was only just detectable. If the interval is appreciable (over $0.03 \mathrm{sec}$.) in the presence of a gradient of $90 \mathrm{~mm}$. $\mathrm{Hg}$ or more, one must suspect an associated pulmonary stenosis (Fig. 3). This occurred in this series in one of the two subjects with supravalvar stenosis, the gradient across the pulmonary valve being $40 \mathrm{~mm}$. Hg.

\section{Radiological Features}

The cardio-thoracic ratio varied from 0.42 to 0.58 with a mean of 0.5 . There was no correlation between this estimate of heart size and the gradient. Fourteen of the 22 patients with valvar stenosis had radiological evidence of post-stenotic dilatation of the aorta and this was confirmed at operation. In the remaining eight, a post-stenotic dilatation was demonstrated at operation in six. Of the four with subvalvar stenosis, dilatation was reported in all and observed at operation to be large in one and small in three. There was no evidence of dilatation radiologically or at operation in the two patients with supravalvar stenosis.

\section{Electrocardiographic Features}

In order to establish the relationship between the cardiographic evidence of left ventricular activity and gradient, the sum of the $S$ and $R$ waves in the commonly used combinations of precordial leads was correlated with gradient (Table III). Gradients of over $60 \mathrm{~mm}$. $\mathrm{Hg}$ were taken as significant and a combined deflection of over $35 \mathrm{~mm}$. was accepted as evidence of excessive left ventricular activity. It is concluded that the taller of the $S$ waves in $V_{1}$ and $V_{2}$ plus the taller of the $R$ waves in $V_{5}$ and $V_{6}$ offers the best correlation. This minimizes the chances of underestimating the severity of the lesion, especially in the young child. At this age an entirely normal cardiogram may be seen in a child with severe stenosis. This cardiographic evidence of left ventricular hypertrophy is not strengthened when

TABLE III

CORRELATION BETWEEN CARDIOGRAPHIC EVIDENCE OF LEFT VENTRICULAR ACTIVITY AND PEAK SYSTOLIC

\begin{tabular}{|c|c|c|c|}
\hline Leads & $\begin{array}{l}\text { Correct } \\
\text { Estimate }\end{array}$ & $\begin{array}{c}\text { Under } \\
\text { Estimate }\end{array}$ & $\begin{array}{c}\text { Over } \\
\text { Estimate }\end{array}$ \\
\hline $\begin{array}{l}S V_{1}+R V_{6} \\
S V_{1}+R V_{5} \text { or }{ }_{6} \\
S V_{1} \text { or }{ }_{2}+R V_{5} \text { or } 6\end{array}$ & $\begin{array}{l}21 \\
29 \\
30\end{array}$ & $\begin{array}{r}18 \\
9 \\
4\end{array}$ & $\begin{array}{l}1 \\
2 \\
6\end{array}$ \\
\hline
\end{tabular}

the additional criteria of Scott, Seiwert, Simon, and McGuire (1955), Scott (1960), and Selzer, Ebnother, Packard, Stone, and Quinn (1958) are taken into account. Campbell and Kauntze (1953) stated that unipolar limb leads show evidence of left ventricular hypertrophy and strain earlier than precordial leads. All cardiograms from the group of 40 subjects were examined from this point of view. In 33 the difference was not significant and in the remainder abnormalities appeared rather earlier in AVF in four, and in $V_{5}$ or $V_{6}$ in three subjects. It is concluded that no additional information is obtained from the unipolar limb leads in the child with aortic stenosis.

The characteristic cardiographic features of aortic stenosis in the child are illustrated in Fig. 4. When the sum of the $R$ and $S$ deflections exceeds $35 \mathrm{~mm}$. and the $T$ wave is negative, the peak systolic gradient is over $60 \mathrm{~mm}$. $\mathrm{Hg}$ without exception. However, in contrast to the adult, relatively few children with this order of stenosis have negative $T$ waves. The majority have a combined $\mathbf{R}$ plus $\mathbf{S}$ deflection which approaches, or more frequently exceeds $35 \mathrm{~mm}$. and a small positive $T$ wave of 0 to $2 \mathrm{~mm}$.

There is a fairly well-defined correlation between gradient and the height of the $T$ wave in leads over the left ventricle (Fig. 5). The majorit of children with gradients over $60 \mathrm{~mm}$. $\mathrm{Hg}$ have positive $T$ waves. This contrasts strongly with the position in the adult where nearly all with this order of stenosis have negative $T$ waves (Fig. 6). This suggests that progressive changes are taking place in the ventricle and it therefore seemed important to establish if cardiographic changes with age were related to the severity of stenosis. The cardiograms of all children on whom gradients had been measured were therefore analysed for the period of years during which they attended the clinic. Abnormalities were found chiefly in those with peak systolic gradients over $60 \mathrm{~mm}$. Hg and the results are therefore presented in the form of a comparison between the group with gradients below and the group with gradients above this level. The changes with age in $S V_{1}$ and $\mathbf{R} \mathbf{V}_{6}$ for the low-gradient group are shown in Fig. 7. The values nearly all lie within the normal ranges laid down by Ziegler (1951) and there is no trend with age. In the high gradient group (Fig. 8), the majority lie within the normal ranges below the age of 10 years but over this age there are an appreciable number of abnormally large $\mathbf{R}$ and $\mathbf{S}$ deflections. When the $T$ wave in $V_{6}$ is treated similarly for the lowgradient group, again nearly all values lie within 
FIG. 4. Correlation between gradient and cardiographic evidence of left ventricular activity: $S V_{1}$ or $_{2}+R V_{5}$ or ${ }_{6}=$ taller of the $S$ waves in $V_{1}$ or $V_{2}$ plus taller of $R$ waves in $V_{5}$ or $V_{6}$; open circles $=$ gradients 10 to $50 ;$ dots $=$ gradients 60 to 166.
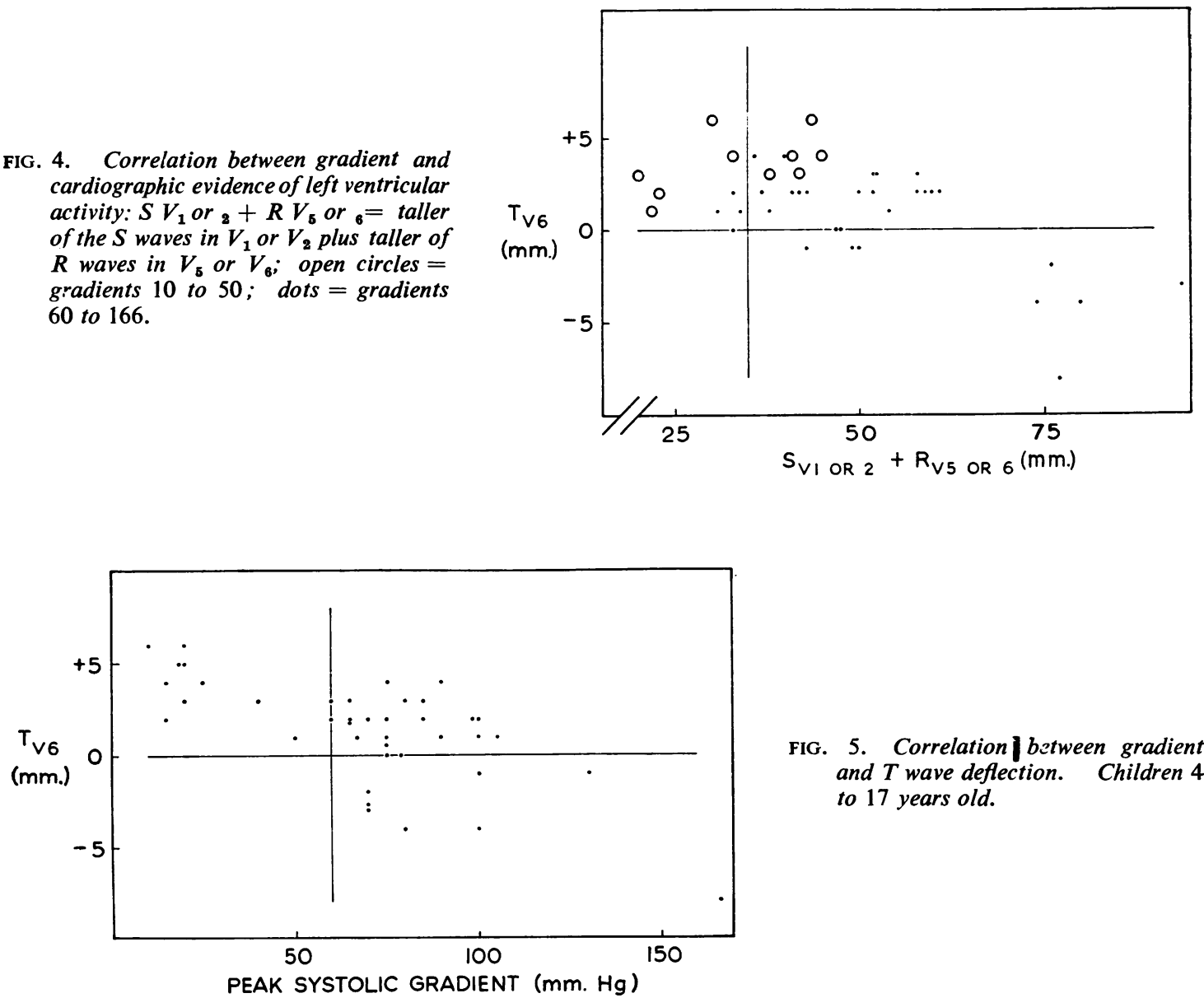

FIG. 5. Correlation batween gradient and $T$ wave deflection. Children 4 to 17 years old.

FIG. 6. Correlation between gradient and $T$ wave deflection. Adults aged 26 to 63 years with pure aortic stenosis of varied aetiology.

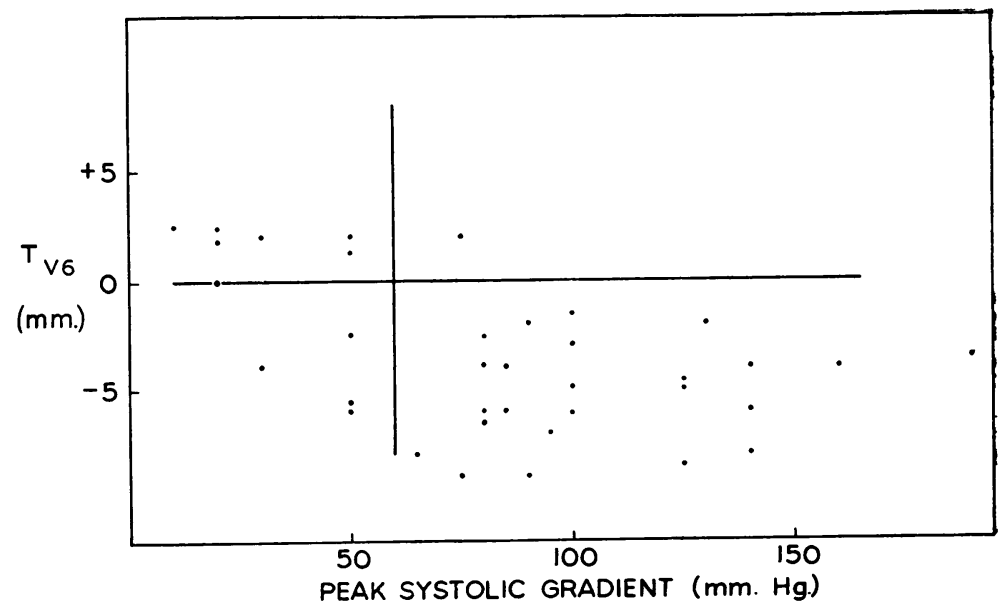




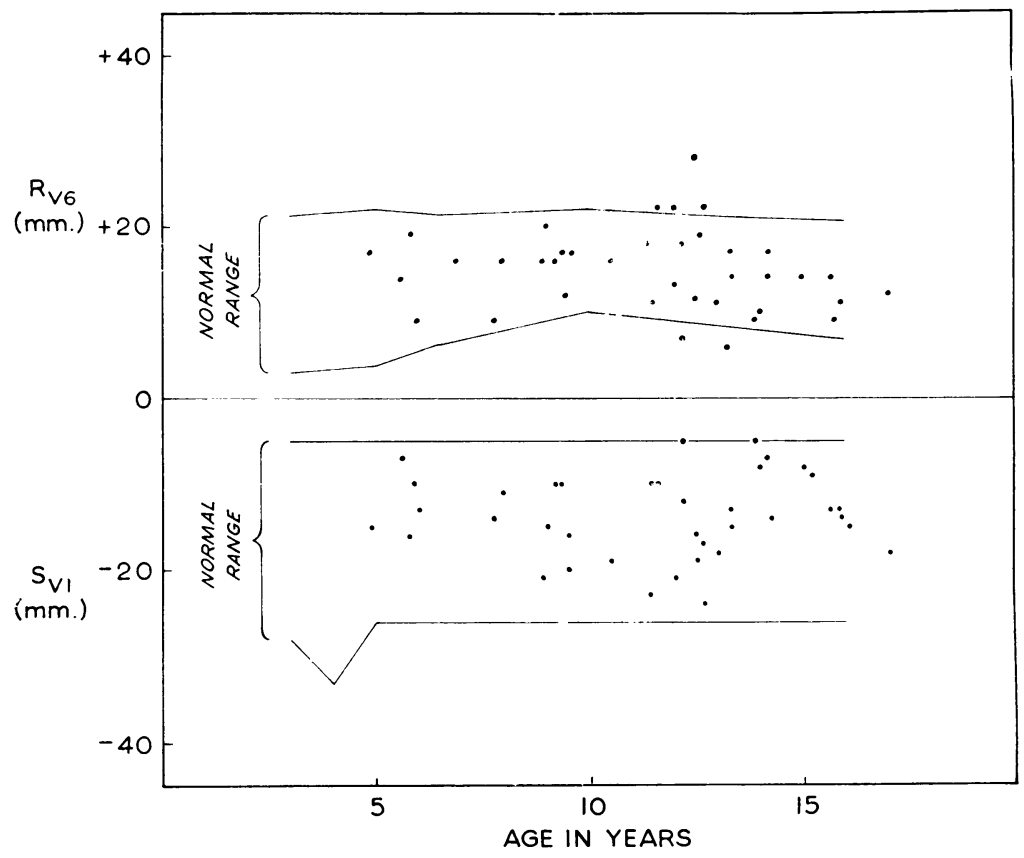

FIG. 7. Changes with age in $S V_{1}$ and $R V_{6}$. Observations on 10 children with gradients of 10 to $50 \mathrm{~mm}$. Hg. Normal range $=98 \%$ confidence interval or observed range (Ziegler, 1951).

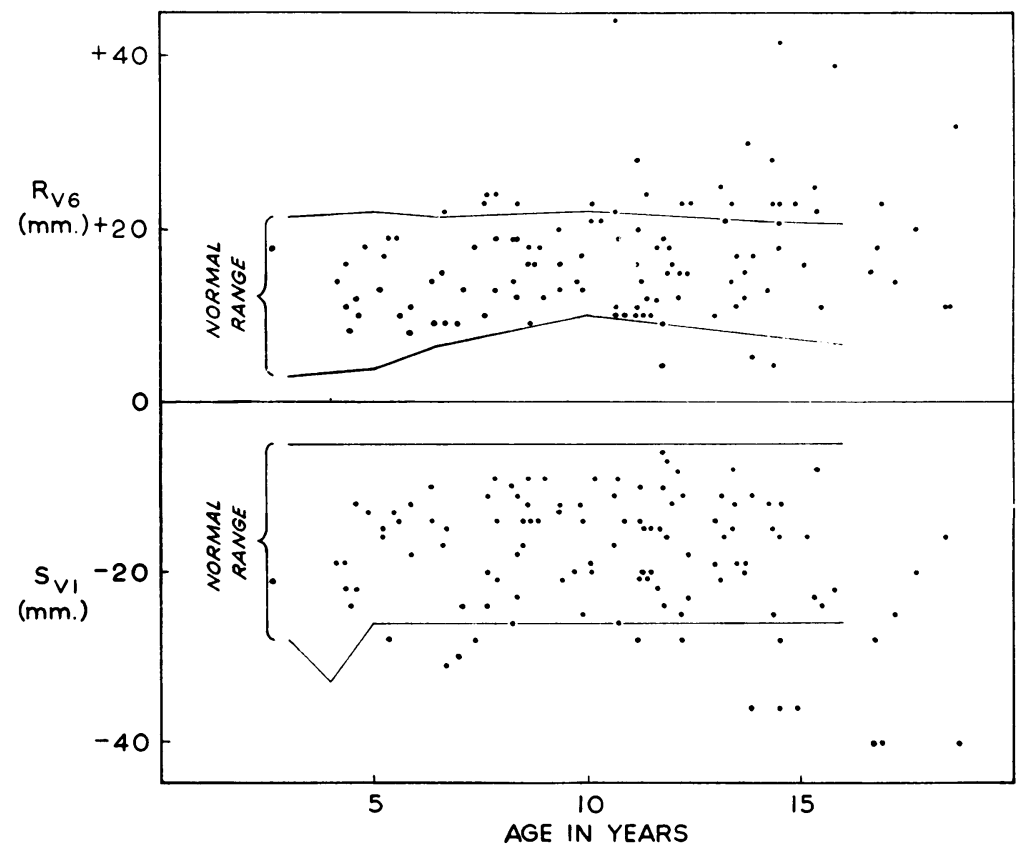

FIG. 8. Changes with age in $S V_{1}$ and $R V_{6}$. Thirty children with gradients of 60 to $166 \mathrm{~mm}$. $\mathrm{Hg}$. Normal range $=98 \%$ confidence interval or observed range (Ziegler, 1951). 
the normal range (Fig. 9). In the high-gradient group, values tend to be low at all ages and after the age of 10 years there are an increasing number of negative deflections (Fig. 10).

The evidence indicates that progressive cardiographic abnormalities are only likely to occur when the peak systolic gradient exceeds $60 \mathrm{~mm}$. $\mathrm{Hg}$. The tempo with which changes occur varies considerably from individual to individual. In some they are hardly detectable throughout childhood ; in others, marked abnormalities appear in infancy.

\section{Surgical Treatment}

The important features that govern the surgery of the congenital aortic valve are the nature of the valve itself and the myocardial hypertrophy. As at no stage have commissures been present between the valve cusps there is no place for a blind procedure, such as transventricular valvotomy with a splitter, since the line of undeveloped commissure is the strongest part of the valve and indiscriminate tearing of the leaflets will be the usual effect with resulting incompetence. Any operation must be under direct vision of the valve which is most easily obtained through the base of the aorta.

Four patients were operated on by the transaortic route before the present series. Two (aged 3 and 10 years) were approached under hypothermia $\left(30^{\circ} \mathrm{C}\right.$.) with inflow occlusion and both developed ventricular fibrillation. After shock therapy normal right ventricular rhythm returned in one patient, but the left ventricular contraction was so poor and intermittent that maintenance of the circulation was impossible, and in the other fibrillation could not be reverted to normal rhythm. Two other patients (aged 13 and 14 years) were treated under normothermic conditions with inflow occlusion and the valve was satisfactorily divided along the three rudimentary commissures. Both patients survived and the stenosis was relieved but both now have a marked degree of aortic incompetence and it is doubtful if any useful result has been obtained.

The situation was reviewed after surgery on these four cases. It was clear that if the left ventricular myocardium is to tolerate surgery on the valve, as near normal physiological conditions as possible must be maintained. In the first place, as a cardinal principle, where significant aortic obstruction is demonstrated, these patients should have this relieved as soon as possible so that degenerative changes of increasing hypertrophy in the myocardium may be minimal. This would entail as simple an operation as possible, since the greater number of these children, as far as the parents are concerned, are virtually asymptomatic. Secondly, myocardial anoxia must be kept to the 
minimum, as fibrillation occurs more easily and is more difficult to revert than in the normal ventricle. Anoxia induced during the division of the valve must be relieved as quickly as possible and this would best be attained by full coronary artery perfusion immediately after division of the valve independently of any ventricular action. This could only be achieved satisfactorily by using a heart-lung by-pass technique and clamping the incision in the side of the aorta. Individual coronary perfusion through the open aorta was rejected as the area immediately above the aortic valve is small in these children and the coronary cannulae may well obstruct adequate vision of the valve. An extra assistant may well be required to keep these in place. As calcification of the valve is rare at this stage, a prolonged operation to detach calcific plaques and repair valve leaflets would be most unlikely. Furthermore, it was considered that normothermia would be preferable to hypothermia, not only to reduce the likelihood of ventricular fibrillation but also to reduce the perfusion time as ventricular action may well have to be supplemented by partial perfusion for a considerable time before the ventricular temperature is raised high enough to get a ventricular output sufficient to maintain an adequate coronary flow. After cross-clamping the aorta division of the valve should be easily accomplished in under ten minutes and at normothermia the ventricle would likely stand this period of anoxia without fibrillating. If a difficult subaortic stenosis required further time then the aortic incision could be clamped, the cross-aortic clamp released, a coronary perfusion performed, and then the aorta re-opened. Finally, our experience with division of the pulmonary valve (Edwards, 1960) had shown us that a bicuspid division of that valve would provide relief of the stenosis without the development of incompetence, whereas division of all commissures would result in a degree of incompetence of which the longterm effect must be viewed with concern. From examination of the structure of the congenitally stenosed aortic valve, it appeared clear that only a bicuspid division should be attempted, extending to just $2 \mathrm{~mm}$. from the valve ring, as the resulting two leaflets then have enough peripheral attachment to prevent them turning back towards the ventricle with the diastolic aortic pressure. The $2 \mathrm{~mm}$. ring of fibrous tissue at the periphery prevents the ring from dilating and drawing the edges of the leaflets away from each other. The types of incisions recommended are shown in Fig. 11. Based upon these concepts, 27 children between the ages of 4 and 17 and one adult aged 26, who had been known to have aortic stenosis for 12 years and who now had a calcified valve with severe dyspnoea and angina, were operated upon. All had a gradient across the aortic valve between 60 and $110 \mathrm{~mm}$. $\mathrm{Hg}$ (Table I).

Surgical Technique.-A medium sternotomy is performed and the heart exposed. The aorta is dissected and a tape passed around it. After heparinization the superior and inferior venae cavae and femoral artery are cannulated and a left atrial drain inserted to prevent pulmonary congestion if ventricular fibrillation should ensue. The cannulae are connected to the heart-lung machine (Melrose). The adventitia on the aorta is dissected back over the proposed line of incision, which is 3 to $4 \mathrm{~cm}$. long and starts $1 \mathrm{~cm}$. above the valve. Stay sutures are inserted on each side of the incisional line. A Satinsky clamp is loosely placed across the aorta proximal to the innominate artery. The perfusion is started and partial, then complete, by-pass established. A small incision is made in the aorta and the intracardiac sucker inserted; at the same time the cross-aorta Satinsky clamp is closed. The aortic incision is then enlarged to 3 to $4 \mathrm{~cm}$. and retracted gently with the stay sutures and small retractors. The valve is examined and the necessary incision made to convert it into a bicuspid valve and relieve the stenosis, each incision being carried to within $2 \mathrm{~mm}$. only of the ring. A finger is passed down the outflow tract of the left ventricle to exclude the presence of a subvalvar stenosis. If a thin diaphragm is found this can be split with a pair of forceps and then a dilator, and any residuum excised if necessary. A fibrous stenosis will require excision with scissors and nibbling forceps, great care being taken on the area adjacent to the mitral valve as the septal cusp may be an intimate relation of the stenotic area. If this latter procedure is not completed at the end of eight minutes, the aortic incision is clamped, the crossaortic clamp released, and a full coronary perfusion is given for five to ten minutes until the E.C.G. signs of myocardial anoxia have disappeared. The aorta is cross-clamped again, the lateral incision unclamped and further clearance of the outflow tract is undertaken until the stenosis is completely relieved. The aortic incision is then clamped with a Swan clamp and the cross-aortic clamp released, allowing full coronary perfusion to continue. This continues for a further 10 to 15 minutes until the E.C.G. signs of anoxia have again disappeared, during which time the aortic incision is being sutured with a continuous mattress and then an over and over suture. Finally a slip of Ivalon is placed along the length of the incision and held in place by suturing the detached adventitia over it. If ventricular fibrillation occurs, defibrillation is not attempted until the heart is fully re-oxygenated. Heparin reversal is undertaken with protamine and decannulation performed. When the heart action and pressures have returned to normal 

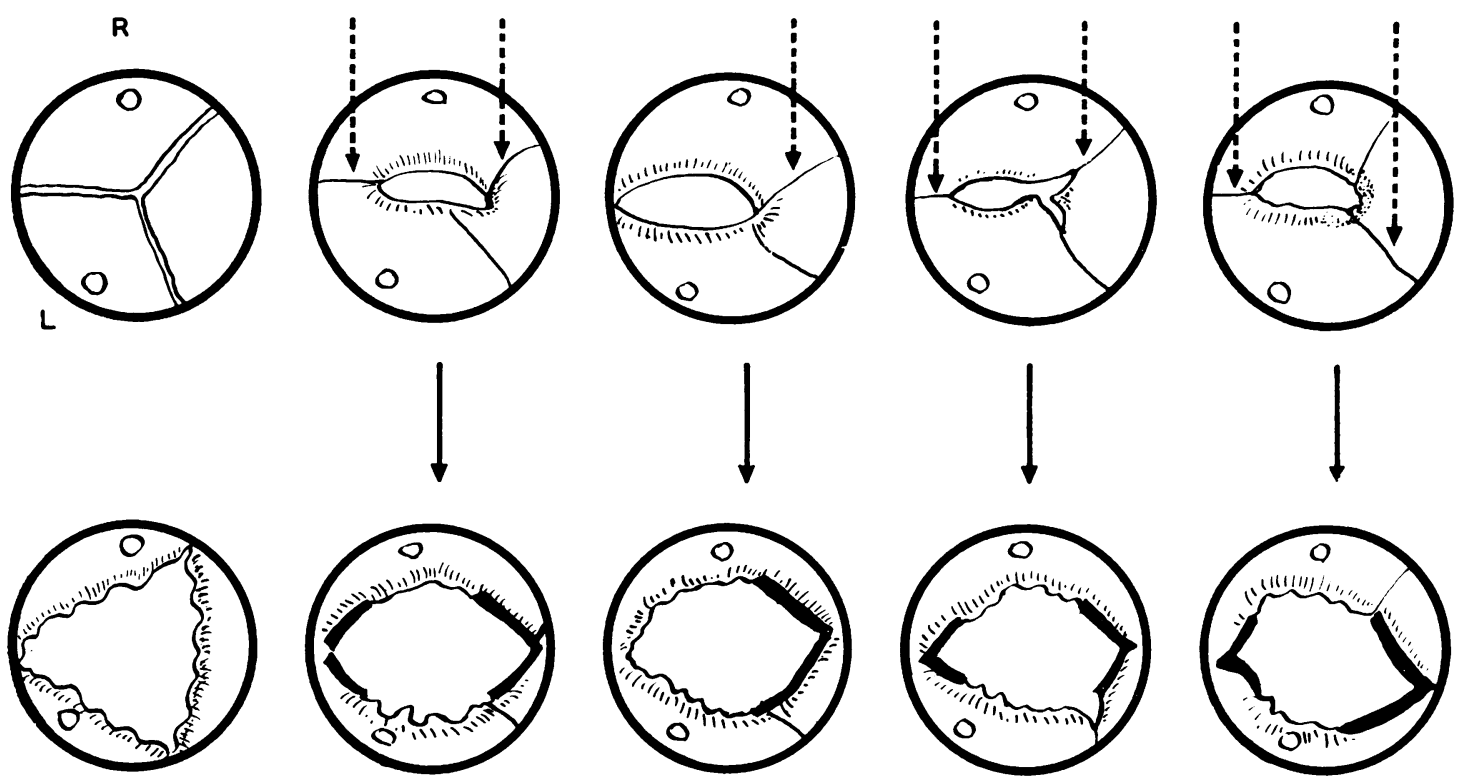

NORMAL VALVE

TYPES OF VALVE INCISIONS

FIG. 11.-Types of valves found at operation. The non-coronary cusp is usually the most rudimentary. The elective area to incise is indicated by the arrows and the resultant opening demonstrated.

the gradient across the valve is rechecked. The left ventricle lumen is most easily entered in these cases by passing the needle into the right ventricle and through the septum directly backwards towards the spine. Finally the chest is closed with very adequate drainage of the mediastinum and one of the pleural cavities.

\section{RESULTS}

Twenty-eight patients were operated upon. Two were found to have a supravalvar stenosis. In both cases the coronary ostia were situated in the funnel-shaped entrance to the stenotic area and excision of the structure was not possible. The insertion of a patch to widen the stenotic area was considered, but the walls were so thick that in order to get a satisfactory lumen more than half the circumference of the aorta would have had to consist of patch. Furthermore, the future of the patch and its suture line in an area which would eventually receive the full impact of the output of the left ventricle was considered to be most problematical. The operation was abandoned in both cases. Four patients had sub-aortic stenosis and of these two had an immediate subvalvar diaphragm and one had two diaphragms at $1 \mathrm{~cm}$. and $3 \mathrm{~cm}$. below the valve, all of which were split easily and effectively with forceps and a dilator.
One patient had a fibrous stenosis $3 \mathrm{~cm}$. below the valve which required excision. Twenty-two patients had valvar stenosis and one of these also had a subvalvar diaphragm. In 19 of the 22 patients the valve ostium was essentially bicuspid, and in three a rudimentary third commissure was present. The openings varied between 8 and 13 $\mathrm{mm}$. and these were enlarged to create in essence a bicuspid valve 3 to $4 \mathrm{~mm}$. less than the aortic ring. This gave an opening of 20 to $25 \mathrm{~mm}$., depending on the age of the child. Calcification was not present in any valve except in the patient aged 26.

Not all patients have had a check of the gradient across the valve at the end of the operation but, except in one patient with a very muscular outflow tract, the gradient when measured has been found to be between $20 \mathrm{~mm}$. $\mathrm{Hg}$ and zero. It is felt that gradients taken at this stage can be fallacious and that the only true indication of the result of the operation would be obtained by a further ventricular puncture one year after valve division.

Mortality.-Two patients died. One was a girl, aged 14, who had a subvalvar stenosis easily and effectively opened. She had a tendency to bleed post-operatively, in all some $1,600 \mathrm{ml}$. 
Although this was replaced, there was some difficulty in maintaining a normal systemic pressure and sudden cardiac arrest which was fatal occurred 48 hours after operation.

This case emphasizes the importance of the maintenance of a constant good systemic pressure in the post-operative phase as with the raised coronary resistance any fall in systemic pressure leads to a rapidly decreasing coronary flow, myocardial anoxia, and possible arrest.

The second was a girl, aged 10 , with a valvar stenosis and a gradient of $100 \mathrm{~mm}$. $\mathrm{Hg}$ across the valve and marked strain on the E.C.G. Ventricular fibrillation occurred after division of the valve which took nine shocks to revert. This was one of our early cases and no left atrial drain had been inserted. Lung damage occurred and she died of pulmonary oedema 48 hours later.

This case demonstrates the difficulties of reverting the rhythm on these abnormal ventricles, but the lung damage could have been prevented with adequate venting of the left atrium, which has been adopted in all cases since.

Morbidity.-Four patients developed ventricular fibrillation after relief of the stenosis. No shock was given until at least five minutes of full coronary perfusion had been maintained and the myocardium was a good pink colour. Three reverted easily with one or two shocks but the fourth was difficult, as described above, and subsequently died. It is concluded that ventricular fibrillation is very likely to ensue if the coronary flow is interrupted for longer than 10 minutes in these cases.

Two patients developed a hypertensive state which started after closure of the aorta and persisted for some 48 hours. The systemic systolic pressure was maintained between 175 and $200 \mathrm{~mm}$. $\mathrm{Hg}$ and then gradually fell to normal. The explanation of this is obscure, for there was no evidence of incompetence, and it suggested that the hyperdynamic ventricular action tended to persist even though the obstruction had been relieved.

No other complications of importance occurred in the post-operative stages.

Follow-UP.-Although a fair indication of the situation can be given when the patient leaves hospital, it was found that this was not completely reliable. Occasionally no regurgitant bruit was audible on discharge but a slight one was to be heard on follow-up examination. All patients were examined three to 12 months after operation. One patient, who had a grade 2 (out of four grades) diastolic murmur before operation, but whose systemic pressure was $115 / 80$, now has a marked incompetence with a systemic pressure of $90 / 0$ and his future is dubious. Of the remaining 20 who had valvar stenosis, 10 have a grade 1 (or just audible) murmur, four have a grade 2 , and one a grade 3 murmur. The systemic diastolic pressures and pulse pressures may be considered satisfactory, however (Table I). All cases have a persistent systolic bruit, although much softer, and the thrill is either absent or just palpable. Symptomatically all are well.

Of the four cases of subvalvar stenosis the three survivors are well. One of these patients had a grade 2 aortic diastolic bruit which is now considered to be grade 1 . The significance of this is not clear as the valve appeared normal.

A further assessment in two to three years' time is clearly necessary before any final judgment can be made.

\section{Conclusion}

Previous published series of operations for congenital aortic stenosis have emphasized the danger of the development of aortic incompetence (Marquis and Logan, 1955; Downing, 1956; Swan et al., 1958 ; Spencer, Neill, and Bahnson, 1958), and it is to this aspect that special attention has been given. It is very difficult on inspecting an aortic valve with congenital stenosis of moderate or severe degree to make any forecast as to the functional result that will be obtained after division of the commissures, and it is only on assessing the end results of making a tricuspid or bicuspid valve that a policy can be adopted. Although a bicuspid valve will clearly give less of a pathway out of the left ventricle, this may not result in any gradient except under high flow conditions, and the relative freedom from significant regurgitation following this type of operation has encouraged us to adopt this procedure as a routine.

Bicuspid division of the aortic valve can be accomplished quickly and the interruption of the coronary flow need not be more than 7 to 10 minutes, the main perfusion time being occupied in washing the coronary system free of metabolites after the valve division has been accomplished.

It is found, after cross-clamping the aorta, that the E.C.G. changes of myocardial anoxia occur at a rate proportional to the gradient across the aortic valve, and indicate that the greater the myocardial hypertrophy the less the tolerance of oxygen lack.

The use of hypothermia has been found to be unnecessary and the shortness of interrupted 
coronary flow avoids the development of arrest. This technique we consider to be the simplest and safest in the child, in whom symptoms are minimal or absent, but may not be applicable in the adult where severe calcification of the valve may well necessitate a prolonged operation to remove the plaques interfering with cusp mobility.

The relief of subvalvar stenosis is unaccompanied by any problem of valve incompetence and the post-operative result should be eminently satisfactory.

There is a risk of sudden death in untreated aortic stenosis and the incidence in reported series has varied from 5 to $15 \%$ (Braverman and Gibson, 1957; Marquis and Logan, 1955; Downing, 1956; Ongley et al., 1958). In the present series the incidence is $7 \%$. We were unable to trace three of the 120 children in the series when an attempt was made recently to contact all patients. Cardiographic abnormalities have usually been present when death has occurred, and this risk of sudden cardiac arrest is an additional reason for advising operation when the cardiogram is abnormal.

It appears unlikely that valvotomy will in any way influence the tendency of the abnormal aortic valve to calcify, but there is reason to believe that it will prevent or delay physiological and pathological changes in the myocardium which ultimately lead to heart failure. The cardiographic evidence indicates that progressive changes tend to occur in the child, especially when the peak systolic gradient exceeds $60 \mathrm{~mm}$. $\mathrm{Hg}$, and that by the time adult life is reached nearly all have inverted $\mathrm{T}$ waves in leads over the left ventricle. We accept a gradient of this order as the indication for operation over the age of 3 years irrespective of the cardiographic appearances. Under this age technical difficulties increase and operation is probably only indicated when the gradient exceeds $60 \mathrm{~mm}$. $\mathrm{Hg}$ and the $\mathrm{T}$ waves are diphasic or inverted in leads over the left ventricle.

We do not advise operation at present on children with gradients between 40 and $60 \mathrm{~mm}$. Hg unless the $T$ waves are inverted in these leads. However, significant cardiographic abnormalities do occur in a proportion of them by the time they reach adult life (Hancock and Fleming, 1960). It may well be that in the light of further long-term studies of this group, we may consider it necessary to revise our present indications for operation.

\section{SUMMARY}

The anatomy and physiopathology of aortic stenosis in childhood is discussed based upon clinical, necropsy, and operative findings. One hundred and twenty patients have been studied clinically, 10 necropsies have been available, and 32 patients operated upon.

A gradient of $60 \mathrm{~mm}$. $\mathrm{Hg}$ or more across the valve appears to be a definite indication for surgical relief of the stenosis over the age of 3 years irrespective of symptoms.

A transaortic operation, utilizing perfusion, without hypothermia is a safe and adequate technique in childhood, and has been used in 28 patients.

Bicuspid division of the valve gives relief of the stenosis with satisfactory freedom from significant incompetence.

Our grateful thanks are due to Mr. B. John Bickford for permission to include patients operated upon by him, to Professor John Hay for his continued advice, to Dr. G. Jackson Rees and Dr. Alan Stead for their skill in the perfusion and anaesthetic techniques, to Sister Culshaw and the ward staff for their devoted nursing attention, and to the many paediatricians and physicians who have referred patients to us.

\section{REFERENCES}

Braverman, I. B., and Gibson, S. (1957). Amer. Heart J., 53, 487. Campbell, M., and Kauntze, R. (1953). Brit. Heart J., 15, 179.

Downing, D. F. (1956). Circulation, 14, 188.

Edwards, F. R. (1960). Brit. Heart J., $22,472$.

Goodwin, J. F., Hollman, A., Cleland, W. P., and Teare, D. (1960). Ibid., 22, 403.

Hancock, E. W., and Fleming, P. R. (1960). Quart. J. Med., 29, 209.

Hollman, A., Goodwin, J. F., Teare, D., and Renwick, J. W. (1960). Brit. Heart J., 22, 449.

Lees, M. H., Hauck, A. J., Starkey, G. W. B., Nadas, A. S., and Gross, R. E. (1962). Ibid., 24, 31 .

Marquis, R. M., and Logan, A. (1955). Ibid., 17, 373.

Ongley, P. A., Nadas, A. S., Paul, M. H., Rudolph, A. M., and Starkey, G. W. B. (1958). Pediatrics, 21, 207.

Scott, R. C. (1960). Amer. Heart J., 59, 155.

- Seiwert, V. J., Simon, D. L., and McGuire, J. (1955). Circulation, 11, 89.

Selzer, A., Ebnother, C. L., Packard, P., Stone, A. O., and Quinn. J. E. (1958). Ibid., 17, 255.

Spencer, F. C., Neill, C. A., and Bahnson, H. T. (1958). Surgery, 44,

Swan, H., Wilkinson, R. H., and Blount, S. G. (1958). J. thorac. Surg., 35, 139.

Ziegler, R. F. (1951). Electrocardiographic Studies in Normal Infants and Children. Thomas, Springfield, Illinois.

\section{ADDENDUM}

Six more patients have been operated upon since this article was written, three with valvar and three with subvalvar stenosis. All are wel! and satisfactory. 